\title{
Decadal trends in a coral community and evidence of changed disturbance regime
}

\author{
M. Wakeford · T. J. Done · C. R. Johnson
}

Received: 1 May 2007 / Accepted: 13 July 2007 / Published online: 9 August 2007

(C) Springer-Verlag 2007

\begin{abstract}
A 23 year data set (1981-2003 inclusive) and the spatially explicit individual-based model "Compete ${ }^{\odot}$ " were used to investigate the implications of changing disturbance frequency on cover and taxonomic composition of a shallow coral community at Lizard Island, Australia. Near-vertical in situ stereo-photography was used to estimate rates of coral growth, mortality, recruitment and outcomes of pair-wise competitive interactions for 17 physiognomic groups of hard and soft corals. These data were used to parameterise the model, and to quantify impacts of three acute disturbance events that caused significant coral mortality: 1982-a combination of coral bleaching and Crown-of-Thorns starfish; 1990-cyclone waves; and 1996-Crown-of-Thorns starfish. Predicted coral community trajectories were not sensitive to the outcomes of competitive interactions (probably because average coral cover was only $32 \%$ and there was strong vertical separation among established corals) or to major changes in recruitment rates. The model trajectory of coral cover matched the observed trajectory accurately until the 1996 disturbance, but only if all coral mortality was confined to the 3 years of acute disturbance. Beyond that date (1997-2003), when the observed community failed to recover, it was necessary to introduce annual chronic background mortality to obtain a good match between
\end{abstract}

Communicated by Environment Editor K. Fabricius.

M. Wakeford $(\bowtie) \cdot$ T. J. Done

Australian Institute of Marine Science,

PMB \#3, Townsville MC, QLD 4810, Australia

e-mail: m.wakeford@aims.gov.au

C. R. Johnson

School of Zoology, University of Tasmania, GPO Box 252-05, Hobart, TAS 7001, Australia modelled and observed coral cover. This qualitative switch in the model may reflect actual loss of resilience in the real community. Simulated over a century, an 8 year disturbance frequency most closely reproduced the mean community composition observed in the field prior to major disturbance events. Shorter intervals between disturbances led to reduced presence of the dominant hard coral groups, and a gradual increase in the slow growing, more resilient soft corals, while longer intervals (up to 16 years) resulted in monopolization by the fastest growing table coral, Acropora hyacinthus.

Keywords Resilience - Chronic disturbance . Community structure $\cdot$ Climate change $\cdot$ Diversity

\section{Introduction}

Coral reefs are among the world's ecosystems most at risk from global change, both climate related and from direct pressures of human over-exploitation and pollution (Kinzie and Buddemeier 1996; Hoegh-Guldberg 1999; Kleypas et al. 1999; Hughes et al. 2003). Events that kill extensive areas of coral reefs are increasing in frequency and intensity and include coral bleaching (Hoegh-Guldberg 1999; Kleypas et al. 1999), outbreaks of coral-eating predators (Seymour and Bradbury 1999) and disease (Harvell et al. 2002; Rosenberg and Ben-Haim 2002). In addition, deteriorating coastal water quality can also threaten reef health (Wilkinson 1999; McCulloch et al. 2003).

Coral reefs have evolved within this spectrum of disturbances, with variation in the type, scale, intensity and frequency of disturbance all playing a major role in determining community dynamics and structure (Connell 1978; Huston 1985). Much research has focussed on the 
response of reefs to disturbance, and in particular whether hard corals recover to approximate the communities that existed prior to disturbance (Pearson 1981; Connell 1997) or whether there is a switch to alternative states dominated by macro-algae, soft corals, or "barren" grounds characterised by coralline and filamentous algae (Done 1992; Hughes 1994; Knowlton 1992; Wooldridge et al. 2005). Scientists predict a continued increase in disturbance frequency with dire consequences for coral reefs (HoeghGuldberg 1999; Kleypas et al. 1999; Hughes et al. 2003). It is predicted that most coral reef systems will be experiencing near-annual bleaching events that will exceed the extent of the 1998 bleaching event by the year 2040 (Hoegh-Guldberg 1999). However, a detailed understanding of how coral reefs might respond to changing patterns of coral mortality is unclear.

An indication of likely future changes in coral reefs under altered environmental conditions and disturbance regimes may be gained by investigating changes in the recent past. In particular, it would be valuable to understand past variability in the trajectories of coral cover and composition, and to understand the relative roles of key ecological processes, such as recruitment, growth, survivorship and competition, in driving that variability. In this study, a coupled-lattice model of an area of reef was built and tuned to closely match the observed trajectory of the study area in the period 1981-2003. This provided a basis to understand the role of the various ecological and disturbance processes in structuring the community, and to investigate possible futures for this area in coming decades.

Throughout the lives of corals, there can be significant physical contact and competition for space on the reef. Outcomes of competition can be important in determining the survival of individual corals (Tanner et al. 1994; Sheppard 1985). Dunstan and Johnson (2005) successfully modelled marine epibenthic community trajectories based on the probability distributions describing outcomes of pair-wise competitive interactions, recruitment, mortality and growth rates. This study explored how these same processes have played out (photographic monitoring 19812003), and might shape coral community dynamics in the future (2003-2103), in a $32 \mathrm{~m}^{2}$ area. Processes that play a key role in structuring communities at one time may become less important once disturbance becomes more frequent, leading to lower benthic cover and reduced likelihood of interaction among established colonies than in more crowded sites, and greater availability of space for growth and new colonisation. The study area experienced three major disturbance events in the period 1981-2003. In 1982 there was significant coral mortality from a combination of coral bleaching and crown-of-thorns starfish (Harriot 1985), in 1990 corals were damaged or removed entirely by waves from Cyclone Ivor (van Woesik et al.
1991) while in 1996 corals were significantly affected by predation from crown-of-thorns starfish (Sweatman et al. 1998; Pratchett 2005).

The particular aims of the study were to determine (1) whether local ecological processes affecting corals can be modelled to produce a community trajectory similar to the observed community over 23 years; (2) which processes are most important in determining the trajectory; and (3) the range of variability in predicted trajectories of the modelled community under various disturbance intervals over 100 years.

\section{Materials and methods}

Study site

The study site is at Lizard Island on the Great Barrier Reef, Australia, $30 \mathrm{~km}$ off the north Queensland coast. It is a mid-shelf continental island beyond the reach of river flood plumes, and has been protected as a no-take zone since 1983 (Great Barrier Reef Marine Park Authority 1983). The island has extensive fringing reefs and a large, welldeveloped lagoonal area. The study site $(4 \mathrm{~m} \times 8 \mathrm{~m})$ is located on the southeast fore-reef flat that extends from Bird Islet to South Island (Fig. 1a). It represents a small section of the fore-reef at a depth of approximately $2.5 \mathrm{~m}$ below extreme low tide and is regularly subjected to strong surge. The substratum (Fig. 2a) is a continuous limestone pavement, relatively sediment-free, and with hard corals comprising plating and corymbose Acropora, bushy Pocillopora, small colonies of favids and massive Porites, and soft corals from the family Alcyoniidae. This community type is fairly typical for the southeast fore-reef flat, and although findings from this study site may be similar for other places on the reef, it would be necessary to expand the sampling protocol to include replicate sites to make such inferences. Additional sites around Lizard Island have been established and will be investigated at a later date to expand the scope of this study.

\section{Sampling}

The benthic community within the study site was monitored most years using near-vertical stereo photography (see Done 1981). Photographs were taken on Kodachrome 64 slide film from $\sim 2 \mathrm{~m}$ above the substratum at $1 \mathrm{~m}$ intervals along tape measures stretched between steel pegs within the site (Fig. 1b) using two Nikonos cameras fitted with $28 \mathrm{~mm}$ lenses and mounted $300 \mathrm{~mm}$ apart on a rigid aluminium frame. A $1.9 \mathrm{~m}$ rod with scale object and spirit levels fitted at right angles was used to acquire overlapping 
Fig. 1 Lizard Island study site. a Location map. b Detail of study site. Rectangles are $35 \mathrm{~mm}$ slides, dots represent steel pegs driven into the reef and lines connecting them are tape measures laid during photography. Shaded rectangles represent the subset of slides analysed using photogrammetry software to derive data for rates of growth, recruitment, mortality and interaction outcomes
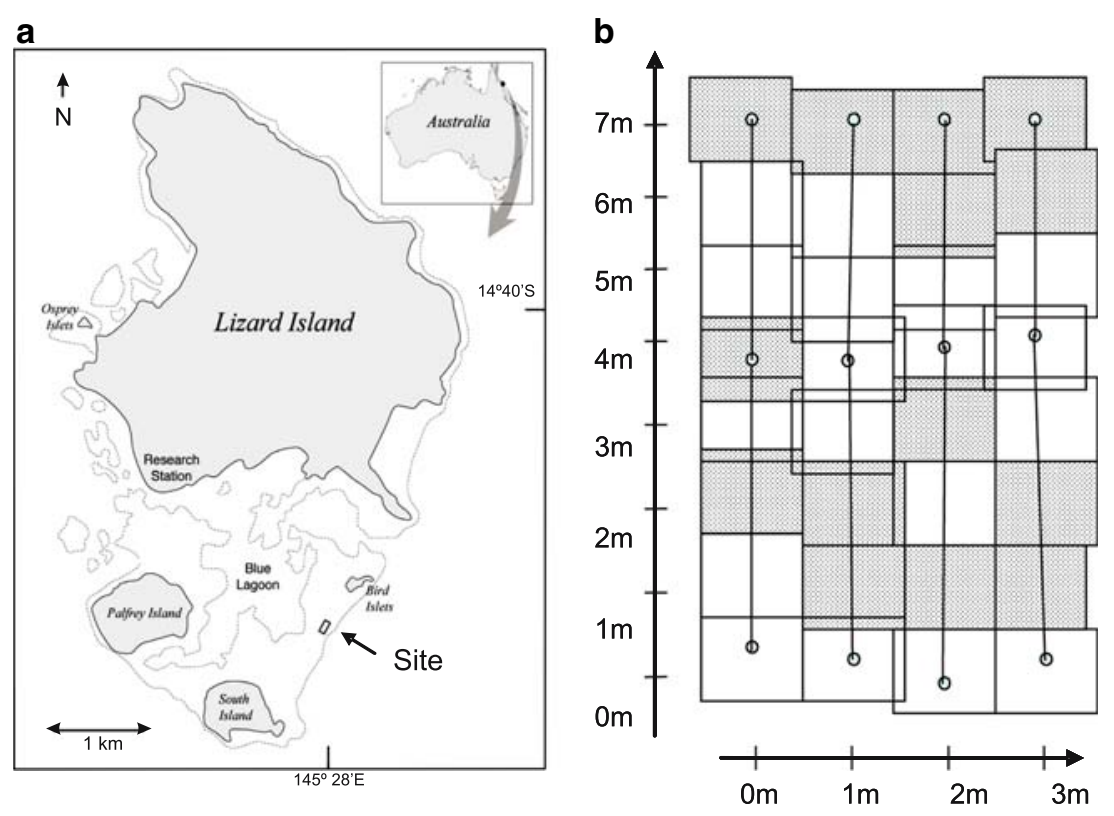

Fig. 2 Lizard Island study site. a Photo mosaic of 32 images comprising the site in 1981 , approximate area $4 \mathrm{~m} \times 8 \mathrm{~m}$. b Base map in Compete ${ }^{\circledR}$ derived from point sampling of a. c Detail of colony outlines generated using Intergraph ImageStation ${ }^{(}$photogrammetry software

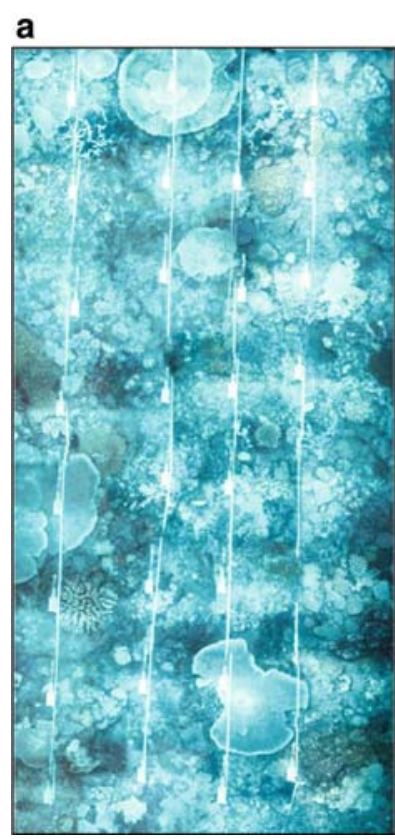

b

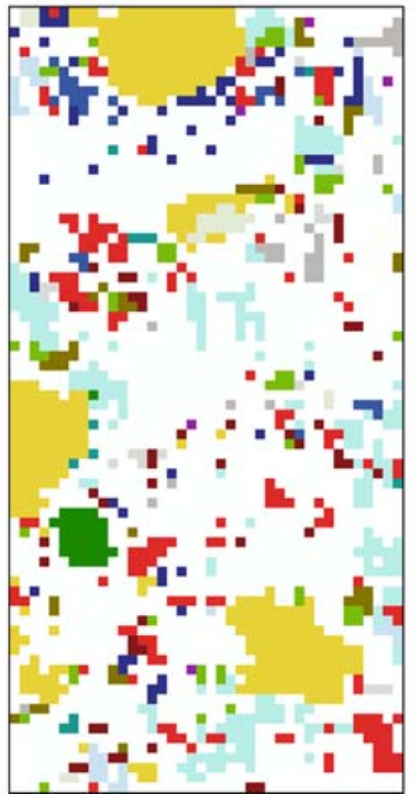

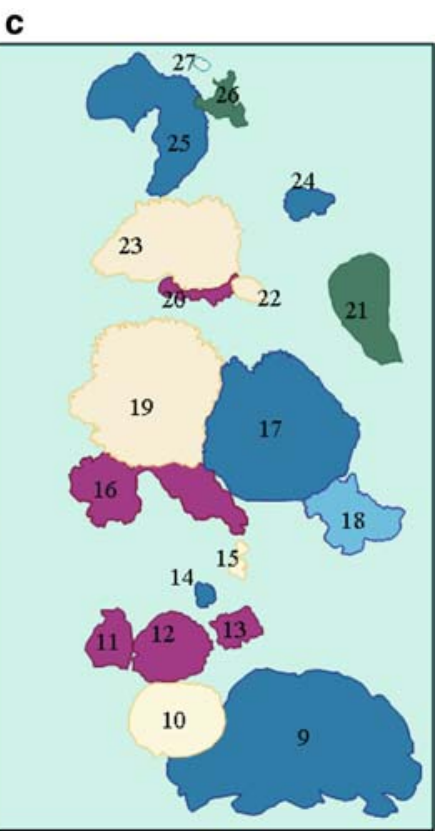

stereo pairs of the entire site in 16 of the 23 years between 1981 and 2003 (Fig. 2a).

The photographic slides were digitised (file size $\sim 27 \mathrm{MB}$ ) and analysed using two methods: (1) a point sampling method to map and quantify changes in community structure based on empirical data, and (2) stereo observation and photogrammetry to quantify rates of growth, mortality, recruitment and outcomes of inter-specific interactions to paramaterise the models. In the point sampling, each image pair (32 pairs per year) was viewed stereoscopically and the benthos underlying a $10 \times 10$ grid of evenly spaced points was identified to the highest possible taxonomic level before assigning it to one of 17 physiognomic groups. This procedure provided an estimate of percentage cover of each physiognomic group through time (the "observed" trajectories) and also a base map for the spatial model (1981 only). For the base map, the observed benthic attribute at each point was assumed to fully occupy a $10 \times 10 \mathrm{~cm}$ square (Fig. 2b). Stereo observation and photogrammetry were then used to provide estimates of growth, mortality, recruitment and outcomes of inter-specific interactions for each physiognomic group. 
Subsets of images (the same 14 pairs on each trip, see Fig. 1b) were displayed on a flat monitor using photogrammetry software (Intergraph ImageStation ${ }^{\circledR}$ Stereo Softcopy Kit, see http://www.intergraph.com), viewed through liquid crystal shutter eyewear (Stereographics CE3 ), and mapped on-screen using a mouse-driven cursor (Fig. 2c). The time-series of colony sizes and status (live, dead, injured) were then used to compute parameter rates for recruitment, growth, mortality and pair-wise interaction outcomes to be used in the spatial model "Compete ${ }^{\Theta}$ (available at http://www.zoo.utas.edu.au/CJPblist/ PublistCJohnson2.htm).

\section{Modelling the community trajectory}

The $8 \mathrm{~m} \times 4 \mathrm{~m}$ base map of the 1981 coral community was represented on a spatial landscape of $320 \times 160$ cells, with each cell representing a real area of $25 \times 25 \mathrm{~mm}$ on the reef. The "Compete" ${ }^{\complement}$ " model was then run on the landscape for either 23 or 100 years at time steps of 1 month. Compete $^{\odot}$ uses a probabilistic (stochastic) cellular automaton as its kernel, with growth, mortality, recruitment and disturbance expressed as conditional probabilities of cell occupancy at each time-step. The terms "site" and "model" are used below to distinguish between the empirical data (from photographs) and the modelled outputs.

At the site, measurements for growth were derived for each physiognomic group from annual change in colony area (until the colony died or reached 2003). Growth was converted from change in area to a rate of linear extension (based on change in equivalent circle diameter) to a monthly probability of growth into an empty cell. Average and variable growth were trialled in the model. Compete ${ }^{(}$ models variable growth rate by assigning new recruits a growth rate selected randomly from a given range of growth rates. This range was defined as the average growth \pm 1 standard deviation.

Mortality in a given physiognomic group was defined in the model by (i) the probability of mortality for that group, which applied to every cell of that group in each time-step; and (ii) the size of the mortality event, which defined the maximum number of contiguous cells of the same group that were removed in a single mortality event. At the site, the probability of mortality (i) was derived from the number of whole colonies dying per year for each group. The size of the mortality event (ii) was set to the average size of colonies that died across all groups (the model does not allow for different size mortality events to be set for each group). Therefore, to account for differences in the size of the mortality events among groups, a correction factor was applied to mortality probability. For example, if the size of the mortality event for a given group was only half as big as the set mortality size, its mortality probability was halved.

Recruitment occurred only in empty cells on the landscape and was set to "open" whereby recruitment did not depend on the relative abundance of physiognomic groups on the current landscape. Instead, a group was selected at random from any that had existed in the system, and it recruited to the empty cell with a probability defined by its recruitment rate. At the site, recruitment rate for each group was estimated by converting the average number of recruits/year/area to the monthly probability $(0-1)$ that a group would recruit to an unoccupied cell on the model landscape.

Outcome of interactions between each pair of physiognomic groups was assessed at the site and converted to a probability of win, loss or stand-off. In the model, if a central cell was occupied by a group $Y$, then a neighbouring cell $X$ was chosen at random, and group $X$ overgrew group $Y$ (the central cell) with probability $\operatorname{Pr}_{X Y}{ }^{*} G_{X Y}$ where $P r_{X Y}$ was the probability of $X$ winning an encounter with $Y$, and $G_{X Y}$ was the growth rate of $X$ over $Y$. All of the 136 possible pair-wise combinations among the 17 groups at the site were considered in deriving probabilities of win, loss or stand-off. However, reasonable data (defined arbitrarily as $n \geq 8$ independent observations) were available for only 43 interactions. All other interactions were assigned equal probabilities of win, loss and standoff.

The period 1981-2003 was divided into 6 periods to distinguish between years of "acute disturbance" and "inter-disturbance" periods as follows:

1982: coral bleaching and crown-of-thorns starfish (acute disturbance),

1983-1989: inter-disturbance period 1,

1990: cyclone damage (acute disturbance),

1991-1995: inter-disturbance period 2,

1996: crown-of-thorns starfish (acute disturbance),

1997-2003: inter-disturbance period 3.

The differing trajectories of each of these periods were simulated using (1) rates of growth, mortality and recruitment determined separately for each period and (2) probabilities for outcomes of competitive interaction based on observations averaged over the six periods. The goodness of fit of the modelled to the observed trajectory of coral community structure was compared graphically. The best-fit trajectory was obtained by experimenting with combinations of average growth rate and variable growth rate (a random selection from a range defined by average $\pm 1 \mathrm{SD}$ ), and the presence or absence of "background mortality". These best-fit settings were then fixed for subsequent runs of the model, which investigated 
sensitivity to varying rates of recruitment and outcomes of interactions.

\section{Effects of recruitment and interactions}

For recruitment, the following scenarios were examined: (1) failed recruitment (all recruitment set to zero); (2) the observed mean recruitment rate across all physiognomic groups; (3) double the observed mean recruitment rate of each physiognomic group; and (4) tenfold the observed recruitment rate of each physiognomic group. For competitive interactions, the observed interaction outcomes were compared with three arbitrary scenarios, namely, (1) equal probability of win, loss or standoff (outcomes as $33: 33: 34 \%$ ), (2) $100 \%$ standoff (outcomes as 0:0:100\%), and (3) randomly determined probabilities of win and loss, with no standoffs allowed (outcome as $[$ win $]+[$ loss $]=100 \%)$.

Effects of changed disturbance frequencies projected over 100 years

Effects of various disturbance intervals on the modelled community were simulated over a 100 year period, with disturbance fixed at regular intervals of 2, 4, 6, 8 and 16 years. Each disturbance was defined using the average of parameter rates determined for the three disturbance years $(1982,1990,1996)$. All inter-disturbance periods were defined by the parameters averaged over all other years, except for background mortality, which was set to zero (see "Results"). The 1981 base map provided the starting spatial configuration, and the first disturbance occurred at year 1 in all cases followed by the requisite number of inter-disturbance years, i.e., for a 16 year disturbance frequency, 1 year with disturbance followed by 15 years without disturbance, repeated until reaching 100 years. Immediately prior to each disturbance the model community composition was recorded and compared to pre-disturbance communities from the observed trajectory (January 1981, 1989, 1994, 1995 and 2002).

Analyses to compare observed and model trajectories

Absolute percent cover data was generated for the observed (based on point-sampling empirical data) and model trajectories for each physiognomic group. These data were square-root transformed to down-weigh the importance of the highly abundant species, and a Bray-Curtis similarity matrix was generated among years. Changes in composition through time were followed using Kruskal's non-metric multidimensional scaling (NMDS) of the predisturbance abundances of each group. A Procrustes rotation analysis was used to assess the degree of concordance between the modelled trajectories and the observed trajectory. Procrustes analysis works by scaling, rotating and dilating one ordination solution and then superimposing it on the second, maximising the fit between corresponding observations. The least-square criterion that minimizes the sum of the squared residuals $\left(\mathrm{m}^{2}\right)$ between two configurations was used; low values for $m^{2}$ indicate strong concordance (Gower 1971). "ProTest", which assesses the statistical significance of the Procrustean fit (Peres-Neto and Jackson 2001), was used with 9999 permutations to assess the significance of pair-wise comparisons of the trajectory for each disturbance interval against the observed trajectory.

The NMDS analysis was carried out using the package MASS in $\mathrm{R}$ version 2.4.1 ( $\mathrm{R}$ Development Core Team 2005, see http://www.r-project.org/). The R package Vegan was used to calculate the Bray-Curtis distance measure, and to undertake the Procrustes and ProTest procedures. Primer 5 (Clarke and Warwick 2001) was used to generate plots of the 100 year NMDS trajectories.

\section{Results}

Observed changes in the study site

Cover of hard corals was $\sim 26 \%$ when the site was first assessed in 1981, and was reduced significantly after each acute disturbance event (Fig. 3a). However, following the disturbances in 1982 and 1990, hard coral cover either regained (post-1982) or exceeded (post1990) previous levels. In contrast, following the acute disturbance in 1996, recovery of hard corals was minimal and cover remained below $24 \%$ for the remainder of observations. Of the 17 physiognomic groups, 14 were hard corals and three were soft corals from the family Alcyoniidae (Table 1). Among the hard corals, the compact bushy Pocillopora damicornis and the table coral Acropora hyacinthus were the most abundant. During inter-disturbance years A. hyacinthus overtopped all other physiognomic groups and quickly dominated cover (Fig. 3a). However, it was also the most susceptible to acute disturbance. Cover of the compact robust coral Acropora "corymbose" also fluctuated markedly but its cover did not attain that of A. hyacinthus. $P$. damicornis maintained fairly constant cover over the observation period as a result of moderate rates of growth, high recruitment and moderate-high mortality 


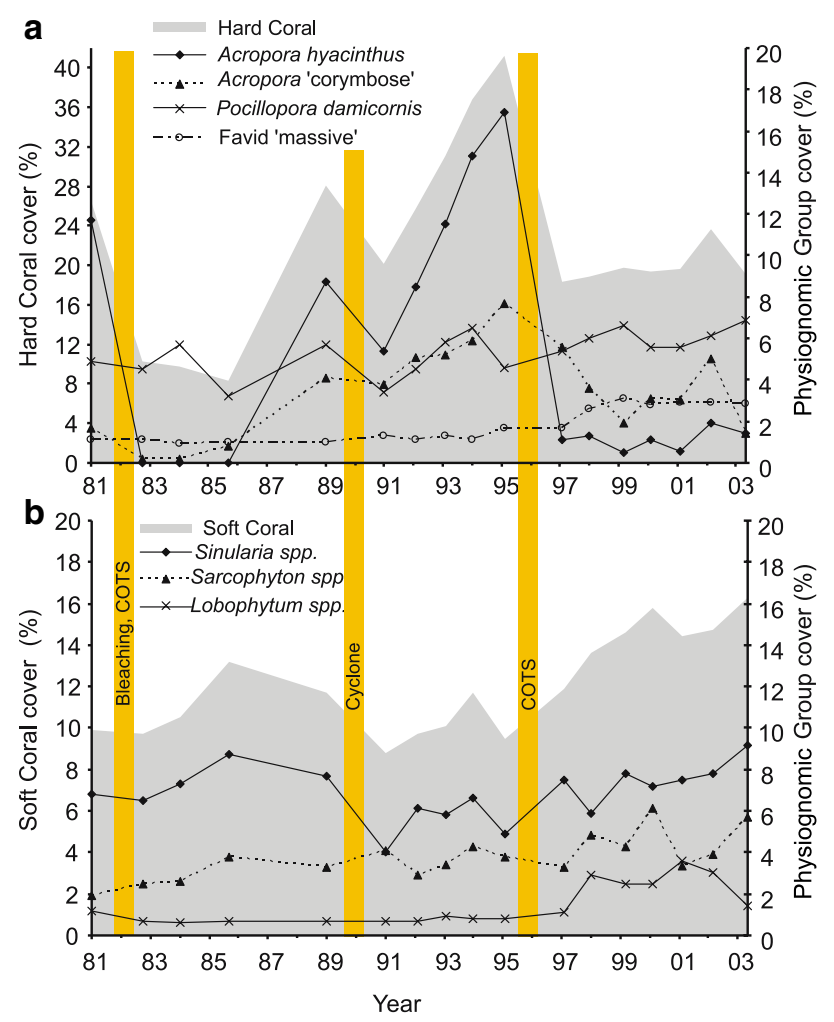

Fig. 3 Temporal patterns in cover of the most abundant corals at the study site, 1981-2003. a Hard corals. b Soft corals. Vertical bars identify discrete disturbance events

during both acute and inter-disturbance years (Fig. 4a-c). Massive favids and Porites were slow growing, longlived and had medium to high recruitment rates. Cover for both these groups remained stable but low throughout the period.

Soft coral cover was only about one third that of hard coral and fluctuated independently of acute disturbance (Fig. 3b), apart perhaps from physical damage caused by cyclone-generated waves in 1990. Two of the three soft corals, Sinularia sp. and Sarcophyton sp., maintained a remarkably uniform cover and population size throughout the study. They had relatively little turnover, moderate to low growth and moderate to high recruitment (Fig. 4a-c). Sinularia sp. had the highest average cover through time $(6.9 \%)$ of all physiognomic groups.

\section{Growth}

Mean growth rates ranged from negative values up to $50 \mathrm{~mm}$ increases in equivalent circular diameter per year (Fig. 4a). Five physiognomic groups had negative growth (due to partial mortality exceeding overall growth), and seven (including all soft corals) had faster mean growth during acute disturbances than inter-disturbance years.
Table 1 The 17 physiognomic groups showing percent cover for the period 1981-2003

\begin{tabular}{lllll}
\hline $\begin{array}{l}\text { Physiognomic group } \\
\text { by family }\end{array}$ & $\begin{array}{l}\text { Average } \\
\text { \% cover }\end{array}$ & Minimum & Maximum & SE \\
\hline Acroporidae & & & & \\
Acropora hyacinthus & 5.0 & 0.0 & 16.9 & 1.5 \\
Acropora "corymbose" & 3.4 & 0.2 & 7.7 & 0.6 \\
Acropora intermedia & 1.5 & 0.0 & 4.4 & 0.4 \\
Acropora millepora & 0.5 & 0.0 & 1.1 & 0.1 \\
Acropora humulis & 0.4 & 0.0 & 1.1 & 0.1 \\
Acropora gemmifera & 0.4 & 0.0 & 0.8 & 0.1 \\
Acropora cuneata & 0.2 & 0.0 & 0.8 & 0.1 \\
Acropora florida & 0.2 & 0.0 & 0.6 & 0.1 \\
Pocilloporidae & & & & \\
Pocillopora damicornis & 5.3 & 3.2 & 6.9 & 0.3 \\
Pocillopora verrucosa & 1.5 & 0.8 & 2.4 & 0.1 \\
Pocillopora eydouxi & 0.2 & 0.0 & 1.0 & 0.1 \\
Faviidae & & & & \\
Favid “massive" & 1.8 & 0.9 & 3.1 & 0.2 \\
Favid “encrusting" & 0.2 & 0.0 & 0.4 & 0.0 \\
Poritidae & & & & \\
Porites "massive" & 1.7 & 1.0 & 2.5 & 0.1 \\
Alcyonidae (Soft corals) & & & & \\
Sinularia sp. & 6.9 & 4.0 & 9.1 & 0.4 \\
Sarcophyton sp. & 3.8 & 1.9 & 6.1 & 0.3 \\
Lobophytum sp. & 1.5 & 0.6 & 3.6 & 0.3 \\
\hline
\end{tabular}

Seven of the eight fastest growing physiognomic groups were in the genus Acropora, and all of the most rapidly growing ten groups were either Acropora or Pocillopora. The massive and encrusting hard corals and the soft corals were the slowest growing groups.

\section{Recruitment}

Massive Porites had the highest recruitment rate and this occurred during acute disturbance years (Fig. 4b). In some cases, new Porites colonies only became visible in the images after upper storey Acropora species had died, making it hard to determine exactly when Porites recruitment had occurred. The five most abundant physiognomic groups had the five highest recruitment rates except for Sinularia sp. which was ninth highest. Recruitment for physiognomic groups ranged from $<1$ to 11 recruits per year over the study area (i.e., $32 \mathrm{~m}^{2}$ ). The average total number of recruits (all groups combined) was 27 per year (which is equivalent to $<0.02 \mathrm{~m}^{2}$ or about $0.05 \%$ of the area of the site). 
Fig. 4 Rates of growth, recruitment and mortality comparing "Acute disturbance" years (black bars) and "Interdisturbance" years (grey bars). Error bars indicate standard error. a Mean growth rates for each physiognomic group expressed as mm year ${ }^{-1}$ increase in equivalent circular diameter. b Mean annual recruitment for each physiognomic group. c Mean percentage of colonies that died annually for each physiognomic group a

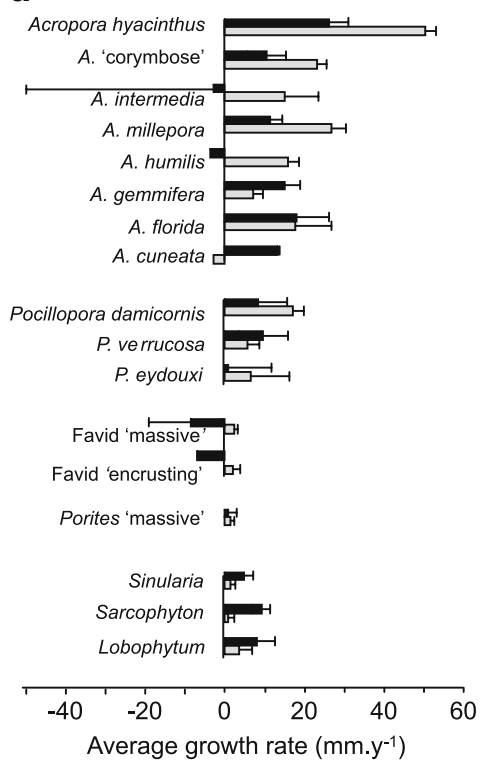

b

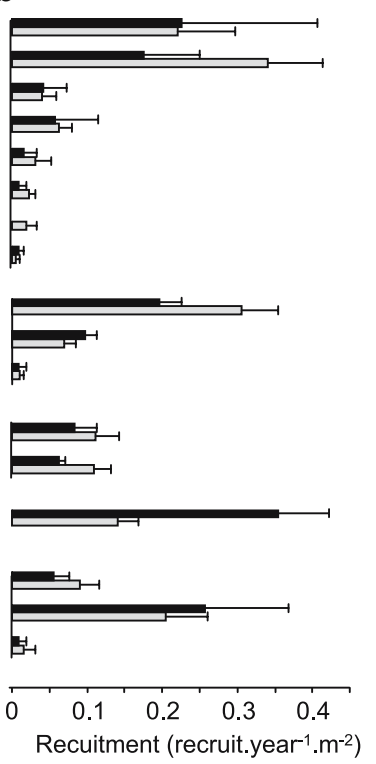

C

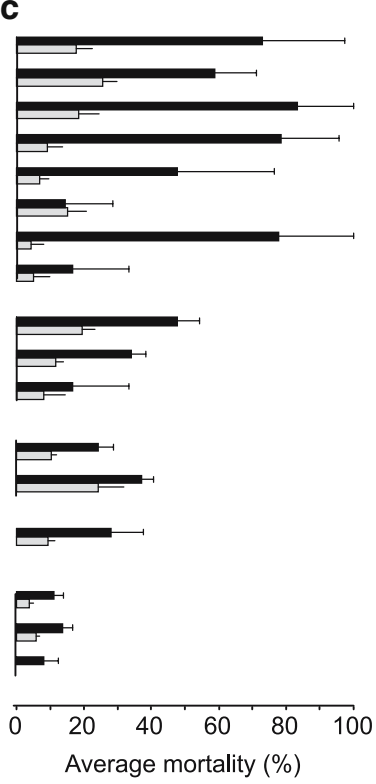

\section{Mortality}

During acute disturbance years, most physiognomic groups (16 out of 17) had higher mortality rates than in interdisturbance years (Fig. 4c). During acute disturbances the fast growing and abundant Acropora species had the highest mortality with slower growing hard and soft corals having lower mortality. During inter-disturbance years, mortality was low and relatively even across all physiognomic groups.

\section{Interactions}

There were 3,445 colony measurements taken of 843 individual colonies over the 16 sample periods. Of these colony measures, 2,363 (68\%) were recorded engaged in one or more interactions with another colony; 1,986 were standoffs (84\%) and 377 were win/loss interactions (16\%) in which one of the contestants suffered a net reduction in area. Of 136 possible pair-wise interactions good data were obtained (i.e., $n \geq 8$ ) for 43 interactions (32\%) (Fig. 5). The tabular coral A. hyacinthus was most successful in competitive interactions, including interactions with the second ranked Acropora "corymbose" and third ranked soft coral, Sarcophyton sp. The soft coral Sinularia sp. and massive Porites consistently lost to overtopping Acropora. These observations defined the probabilities of outcome of inter-specific interactions used in the modelling. Pair-wise combinations that occurred less than eight times $(56 \%$ of the possible number of pair-wise interactions) and thus were relatively rare during the study period were arbitrarily given equal probabilities of win, loss or standoff. Interactions between $A$. intermedia and other physiognomic groups were usually observed as $A$. intermedia overtopping its competitor so that both colonies would co-exist, and in this case the outcome was set to standoff, i.e., 0:0:100\% (12\% of all observed pair-wise interactions).

Physiognomic groups rated by relative percentage

For each of the rates that indicate vigour-growth, survival (complement of mortality) and recruitment - a relative percentage from 0 to 100 was assigned for each physiognomic group (Fig. 6). For both recruitment and growth, relative percentage is defined as the physiognomic group rate/highest rate recorded $\times 100$, such that the highest percentage was 100 . The five top rated physiognomic groups (combining growth, survival and recruitment) during inter-disturbance years were also the five most abundant groups by cover over the entire study period, apart from the most abundant, Sinularia sp. which was rated tenth.

\section{Tuning the model}

The best-fit model trajectory for total hard coral cover was obtained using variable growth throughout, and zero background mortality for all except the last inter-disturbance period, 1997-2003 (Fig. 7; Table 2a), when hard coral failed to recover. For soft corals, selecting between these options had little effect. The effect of changed 
Fig. 5 Outcomes of interactions among 43 physiognomic groups. The graph shows the proportions of wins, losses and standoffs of the first-named physiognomic group (bold lettering) in interactions with the second

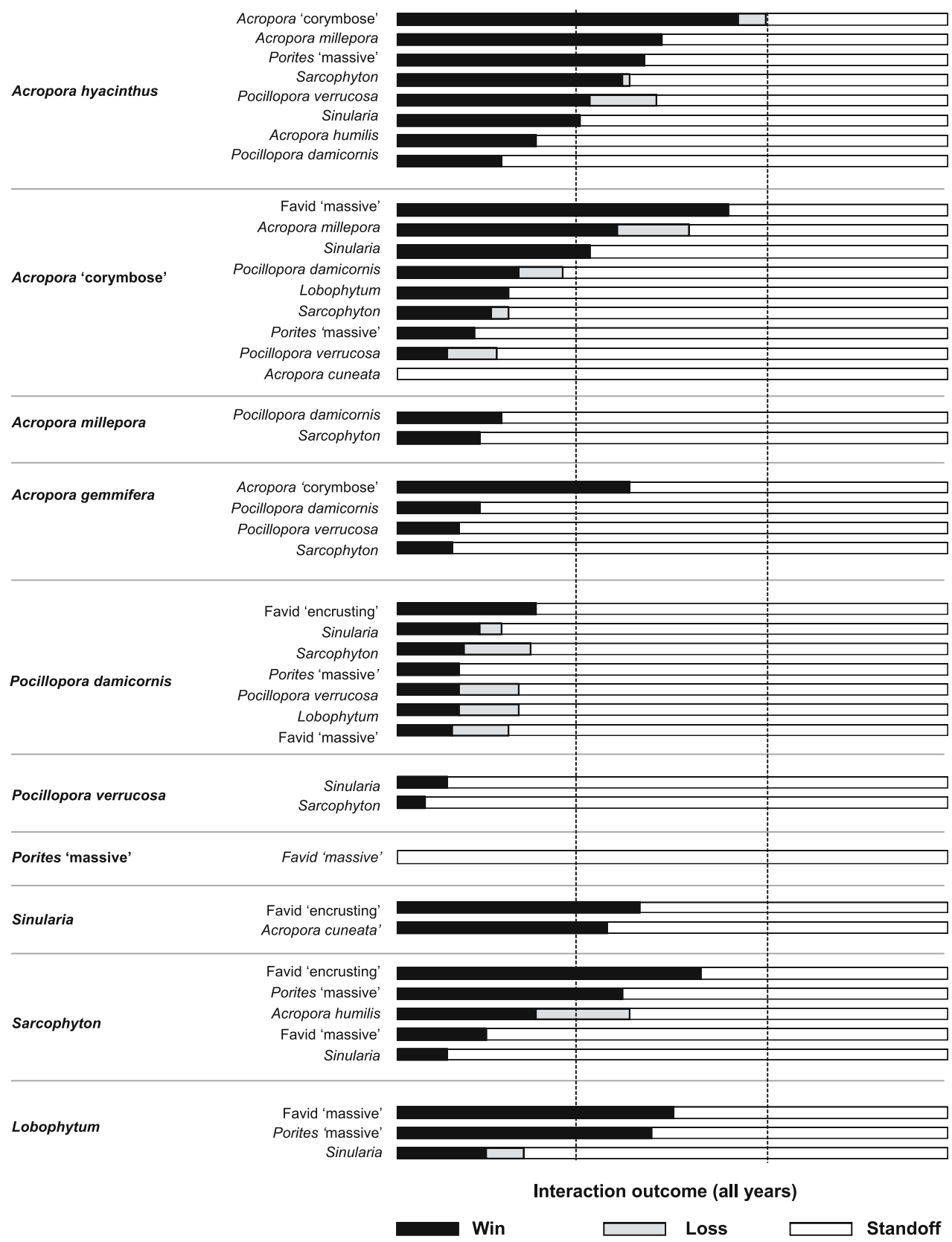

interaction and recruitment scenarios (below) were run using the best-fit model parameters, i.e., variable growth and background mortality included for the last inter-disturbance period.

Effects of interaction and recruitment

The model trajectory based on interaction outcomes measured from the photographs produced a better trajectory than the three models given arbitrary interaction outcomes (Fig. 8a; Table 2b). However, all model trajectories were similar irrespective of the underlying differences in the models that generated them, and all were significantly correlated $(P<0.0001)$ with the "observed" trajectory. Surprisingly, large differences in rates of recruitment did not significantly influence the model trajectory, even when recruitment was increased tenfold across all physiognomic groups (Fig. 8b; Table 2c).

Predictions from 100 year models for changed disturbance frequency

An 8 year disturbance frequency produced community configurations that (in the years just prior to a disturbance) 
Fig. 6 Performance ratings for physiognomic groups in "Acute disturbance" and "Interdisturbance" years. Recruitment, growth and survivorship rates for each physiognomic group are presented on a scale of $0-300$

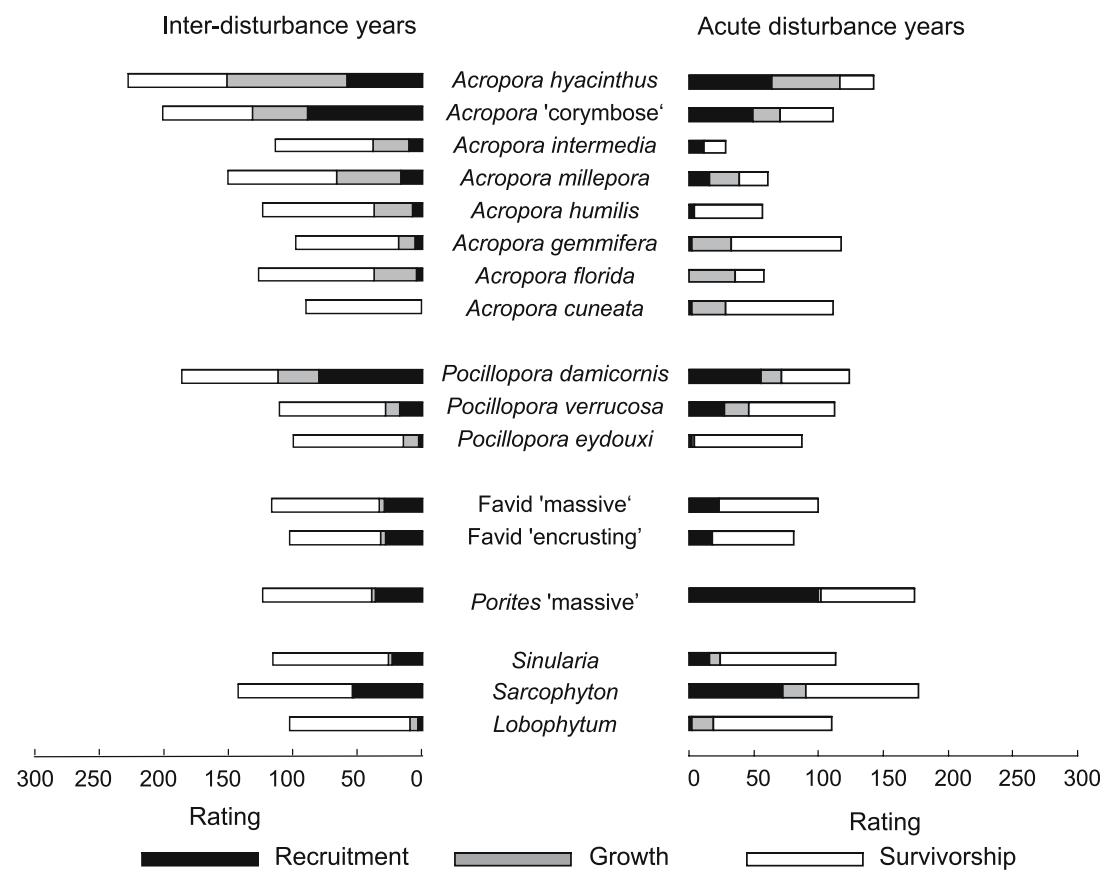

were closest to the least "disturbed" observed communities (Fig. 9a; $P=0.083108$, Table 2d), i.e., dominated by $A$. hyacinthus with contributions from $P$. damicornis and Acropora "corymbose". However, even these diverged markedly from the observed community after about 2030 years (Fig. 9a, d), when physiognomic groups were successively lost as both total coral cover and the monopolization by A. hyacinthus increased. This divergence started sooner with a 16 year disturbance frequency (Fig. 9c), in which A. hyacinthus reached almost $100 \%$ cover after 96 years (Fig. 9a) and only four of the original

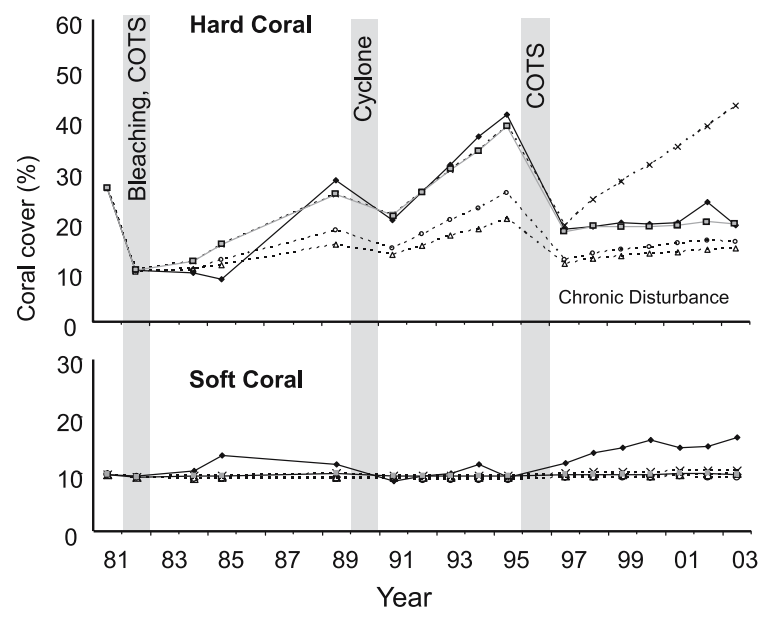

Observed —— Average growth, background mortality ON $\cdots \Delta .$.

Variable growth, background mortality ON: - - - OFF: - -*- ON (1997 - 2003 only): ——-

Fig. 7 Percentage cover of hard and soft corals through time. Comparison of Observed and Model trajectories
17 groups survived. At the other end of the scale, the 2 year disturbance frequency no longer supported a hard coraldominated community after 100 years: most of the low total coral cover (Fig. 9g) comprised soft corals (3 genera; Fig. 9a). Four and six year intervals (Fig. 9f, e) allowed total coral cover to grow with relatively small declines in richness.

\section{Discussion}

Crown-of-thorns starfish, coral bleaching and cyclones are large scale disturbances that can exert considerable impact on mid-shelf reefs of the northern and central Great Barrier Reef (Endean and Cameron 1990; Done 1992; van Woesik et al. 1991; Berkelmans et al. 2004). In this study the key parameters driving a local reef community were measured and it was possible to approximately replicate the dynamics of this community using the individualbased model Compete ${ }^{\odot}$. Various methods were investigated to construct a model that was reasonably faithful in its representation of the community over the 23 year study period. A model based on variable growth rates performed better (closer match to observed) than one based on fixed average growth rates. This allows both exceptional years and size-dependent growth rates to affect community trajectory in a way average growth alone cannot (c.f. Done et al. 2007).

Up until 1996, the 23 year model would only closely reproduce the community trajectory if all modelled mortality was confined to acute disturbance years only. Beyond 
Table 2 Results of the procrustes rotation analyses and ProTest permutation test on the non-metric multidimensoinal scaling (NMDS): observed versus model trajectories

$\begin{array}{lll}\begin{array}{l}\text { Procrustes sum } \\ \text { of squares }\end{array} & \begin{array}{l}\text { ProTest } \\ \text { correlation }\end{array} & \begin{array}{l}\text { ProTest } \\ \text { significance }\end{array}\end{array}$

(a) Model selection

Observed trajectory versus

Average growth, background mortality ON

$\begin{array}{lll}0.06884 & 0.8054 & 0.0001 \\ 0.06527 & 0.8167 & 0.0001 \\ 0.07097 & 0.7987 & 0.0001 \\ 0.03731 & 0.8998 & 0.0001\end{array}$

(b) Interaction

Observed trajectory versus

Model [Best fit model selected from (a) above]

$\begin{array}{lll}0.03731 & 0.8998 & 0.0001\end{array}$

Standoff (outcomes as 0:0:100\%),

0.04739

0.8707

0.0001

Equal (outcomes as 33:33:34\%)

0.04769

0.8698

0.0001

Random (randomly determined probabilities of win

0.04698

0.8719

0.0001

(c) Recruitment

Observed trajectory versus

Model [Best fit model selected from (a) above]

0.03731

0.8998

0.0001

Failed recruitment

0.04857

0.8673

0.0001

Mean recruitment rate across all physiognomic groups

0.04336

0.8825

0.0001

Double the mean recruitment rate of each physiognomic group

0.05379

0.8518

0.0001

Tenfold the recruitment rate of each physiognomic group

0.05029

0.8622

0.0001

(d) 100 year models

Observed trajectory versus

Model [Best fit model selected from (a) above]

$0.01006 \quad 0.8798$

0.050205

Disturbance every 16 years

0.0252

0.6587

0.18162

Disturbance every 8 years

0.0201

0.7406

0.083108

Disturbance every 6 years

0.02137

0.7211

0.12241

Disturbance every 4 years

0.02394

0.6798

0.21732

Disturbance every 2 years

0.02578

0.6486

0.35664

ProTest correlation indicates least squares correlation between observed trajectory and the indicated model set-up (left column). Value of ProTest significance is interpreted in the same way as other statistical " $P$ " values

that date (1997-2003) it was necessary to introduce background mortality into the model to adequately replicate the lack of post-1996 recovery of hard corals. Up until 1996, the study site had been characterised by inter-disturbance periods in which hard coral cover either regained or exceeded previous levels and there was low mortality. It is proposed that this community has entered a new phase in which inter-disturbance "recovery" periods are characterised by chronic disturbance, the model's "background mortality", caused by predation, bleaching and disease. The study community was still recovering from the major 1996 COTS outbreak when region-wide mass bleaching occurred in 1998 and 2002 (Berkelmans et al. 2004), and there were also small numbers of COTS in and near the site at those times (Sweatman et al. 1998; Pratchett 2005; personal observations). Although a number of corals at the site partially bleached during both bleaching events there was not a marked increase in coral mortality (i.e., complete colony death). However, bleaching can reduce coral growth rates, lower fecundity and increase the incidence of disease (Baird and Marshall 2002; Douglas 2003; Harvell et al. 2002), all of which could slow recovery. It is proposed that since 1996 there has not been a typical interdisturbance period free of disturbance in which coral can recover. Instead, various disturbances including residual COTS, low-level bleaching and secondary disease, have impacted the community and kept coral cover stable at low post 1996 disturbance levels. 


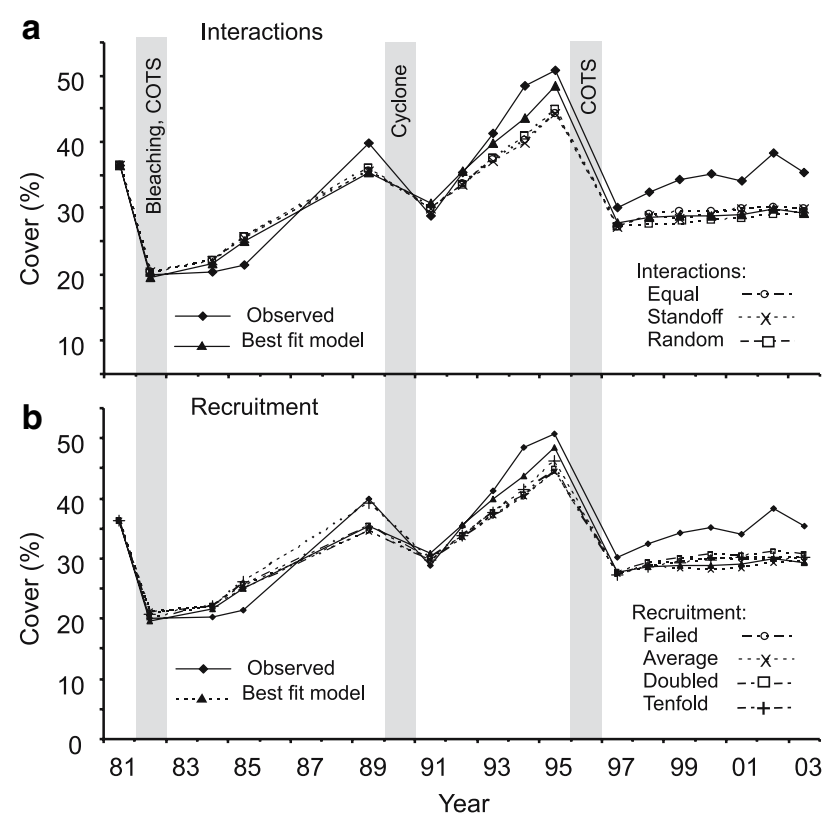

Fig. 8 Percentage cover of hard corals through time. Comparison of Observed and Modelled trajectories. a Effects of the outcomes of interactions. b Effects of changed patterns of recruitment

Neither recruitment rate or interaction outcome had much impact on the model trajectory. Failed recruitment did not cause a significant drop in coral cover, and a tenfold increase in recruitment did not cause a significant rise, over the $\sim 20$ year time frame modelled. Lack of sensitivity to an order of magnitude variability in recruitment reflects very low absolute densities of recruits recorded at the site. (The combined average totalled across all groups was only 27 recruits per year, which, based on a size of $25 \times 25 \mathrm{~mm}$ per model recruit, would cover about $0.05 \%$ of the whole area). Moreover, the 7-8 year interval of recruit growth between disturbances would not be sufficient time for such a low starting percentage, even multiplied ten times, to make a significant contribution to cover compared to the growth of large established colonies. Estimates of recruitment at the site may have been low due to overtopping by A. hyacinthus. It cannot be assumed that this site is generally representative of this habitat in respect of recruitment rates, but this study does show that recruitment cannot be taken for granted as a major driver of observed changes over 2-3 decades; it can take a distant third place to survival and growth of established colonies. For interactions, the conventional wisdom is that they play a major role in shaping coral community structure and dynamics (Lang 1973; but c.f. Bradbury and Young 1983). The present study, however, indicated that interactions were unimportant because frequent disturbances created a surfeit of free space and a very low incidence of competitive interaction before the next disturbance arrived. Average space at the site that was unoccupied by any of the physiognomic groups was about $68 \%$ and maximum coral cover was $40 \%$. In other habitats with comparable colony sizes and low total coral cover, interactions among established corals and other macro-benthos may similarly be of minor importance. In summary, the model suggests that recruitment and inter-specific interactions play a minor role in structuring this community over the 2-decade timescale of observations, and that the major drivers of community structure are disturbance history and growth.

There is widespread concern that global change is degrading the fundamental structure and function of provision of services by, ecosystems of all kinds. For coral reefs, numerous studies have shown that their degradation is often manifest as a persistent phase shift to non-reefbuilding forms such as macro-algae, soft corals or to overgrazed barrens (Done 1992; Hughes 1994; Wooldridge et al. 2005). There was no such tendency observed in the site in the period 1981-2003. However, the need to introduce background mortality to accurately model from 1997 to 2003 suggests that a period of changed disturbance regime and community dynamics may have already commenced.

The model was therefore used to assess community persistence and resilience under a range of different disturbance frequencies. The model in which a major disturbance event arises every 16 years (which is about twice as long as the average observed interval) produced a community that after 100 years became dominated by the hard coral A. hyacinthus (97\%). Although the maximum cover of $A$. hyacinthus recorded at this site is only $17 \%$, a cover of $75 \%$ and more is not uncommon in similar habitats on the GBR (personal observations of the authors). Disturbance every 2 years led to a community that no longer supported hard coral and only low levels of soft coral persisted. There are places where soft corals do monopolize large areas (Dinesen 1983; Fabricius 1997; Ninio et al. 2000) and it is plausible that soft corals could expand in the site, especially under increased disturbance frequency and background mortality levels that limit hard coral recovery. A disturbance interval of 8 years with current observed rates of recruitment, growth and mortality most closely reproduced the mixed hard coral dominance observed at the site in the 1980s and 1990s (but only for the first 20 30 years of the 100 year projection). These 100 year projections did not include the chronic background mortality that this study suggests has retarded hard coral growth since 1996. This raises the question as to the likelihood of a community that suffers chronic background mortality will be able to recover its former abundance, species composition and size class following acute disturbances, or declining even further. 
a

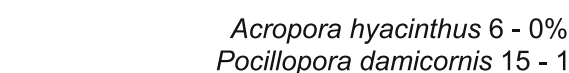
Pocillopora damicornis $15-17 \%$ Acropora 'corymbose' 2 - 19\%

2 years

Sinularia 7 - $5 \%$

Sarcophyton $2-6 \%$

Lobophytum 1 - 8\%

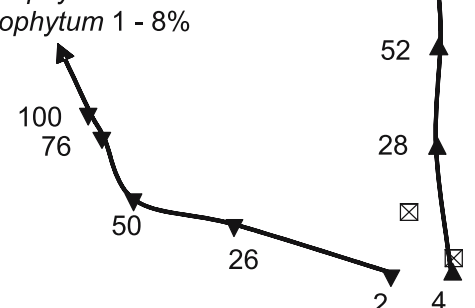

$\begin{array}{llll}2 & 4 & & \\ \nabla & & \nabla & \nabla\end{array}$
Stress: 0.05

\section{6 years}

Acropora hyacinthus 12 - $30 \%$

Pocillopora damicornis 6 - 22\%

Acropora 'corymbose' 3 - 17\%

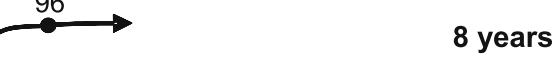

$48 \underset{P}{9} \rightarrow$ Acropora hyacinthus $17-65 \%$

Pocillopora damicornis $8-17 \%$ Acropora 'corymbose' 3 - 5\%

\section{6 years}

16

32

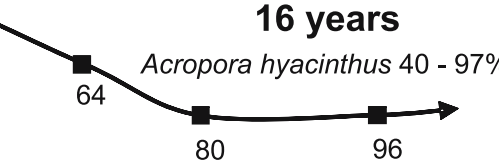

C 16 years

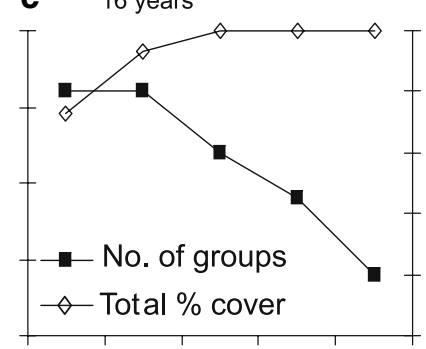

d 8 years

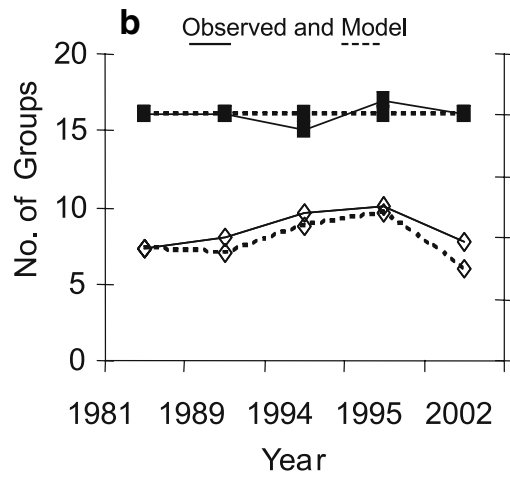

$\begin{array}{lllll}16 & 32 & 64 & 80 & 96\end{array}$

Timescale (years)

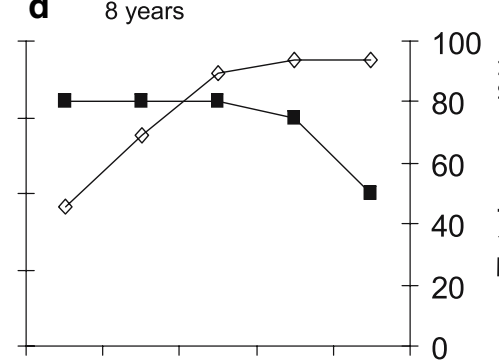

$\begin{array}{lllll}8 & 24 & 48 & 72 & 96\end{array}$
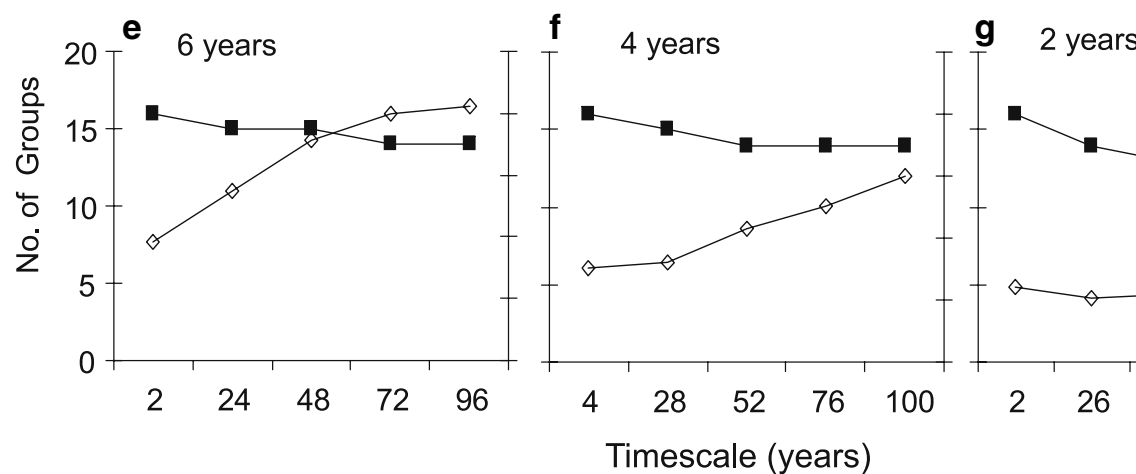

Fig. 9 Predictions from 100 year models for changed disturbance frequency. a NMDS of physiognomic composition and abundance on years preceding disturbances. Disturbance intervals were 2, 4, 6, 8 and 16 years (with numbers along each trajectory indicating year the community data was extracted). The dominant physiognomic groups for each disturbance frequency are listed as a range indicating community composition for the first and last community, respectively, i.e., with an 8 year disturbance frequency, there was $17 \%$

Acknowledgments Thanks to Lyndon DeVantier and Emre Turak for their ongoing assistance with the long-term photographic study of GBR coral communities, and to the master and crews of AIMS ships RV Lady Basten, RV Harry Messel and RV Cape Ferguson. Thanks
Acropora hyacinthus, $8 \%$ Pocillopora damicornis and 3\% Acropora "corymbose", whereas after 96 years they were at 65,17 and 5\%, respectively. The least disturbed communities from 1981 to 2003 (January 1981, 1989, 1994, 1995, 2002) are represented from the Observed and Model communities. b-g Summary of the number of Physiognomic groups and Total percentage cover for each disturbance frequency

are also due to Steve Delean, John Carleton and Shaun Wilson for critical comments and advice on the manuscript. Involvement of C. R. Johnson in the modelling was through the Modelling and Decision Support working group of the CRTR Project. 


\section{References}

Baird AH, Marshall PA (2002) Mortality, growth and reproduction in scleractinian corals following bleaching on the Great Barrier Reef. Mar Ecol Prog Ser 237:133-141

Berkelmans R, De'ath G, Kininmonth S, Skirving WJ (2004) A comparison of the 1998 and 2002 coral bleaching events on the Great Barrier Reef: spatial correlation patterns, and predictions. Coral Reefs 23:74-83

Bradbury RH, Young PC (1983) Coral interactions and community structure: an analysis of spatial pattern. Mar Ecol Prog Ser 11:265-271

Clarke KR, Warwick RM (2001) Change in marine communities: an approach to statistical analysis and interpretation, 2nd edn. PRIMER-E, Plymouth

Connell JH (1978) Diversity in tropical rain forests and coral reefs. Science 199:1302-1310

Connell JH (1997) Disturbance and recovery of coral assemblages. Coral Reefs 16:101-113

Dinesen ZD (1983) Patterns in the distribution of soft corals across the central Great Barrier Reef. Coral Reefs 1:229-236

Done TJ (1981) Photogrammetry in coral ecology: a technique for the study of change in coral communities. Proc 4th Int Coral Reef Symp 2:315-320

Done TJ (1992) Phase shifts in coral reef communities and their ecological significance. Hydrobiologia 247:121-132

Done TJ, Turak E, Wakeford M, DeVantier L, McDonald A, Fisk D (2007) Decadal changes in turbid-water coral communities at Pandora Reef: loss of resilience or too soon to tell? Coral Reefs. doi:10.1007/s00338-007-0265-3

Douglas AE (2003) Coral bleaching - how and why? Mar Pollut Bull 46:385-392

Dunstan PK, Johnson CR (2005) Predicting global dynamics from local interactions: individual-based models predict complex features of marine epibenthic communities. Ecol Model $186: 221-233$

Endean R, Cameron AM (1990) Acanthaster planci population outbreaks. In: Dubinsky S (ed) Coral reefs. Elsevier Science Publishing, New York, pp 419-437

Fabricius KE (1997) Soft coral abundance on the central Great Barrier reef: effects of Acanthaster planci, space availability, and aspects of the physical environment. Coral Reefs 16:159-167

Great Barrier Reef Marine Park Authority (1983) Cairns Section zoning plan and the Cormorant Pass Section zoning plan. James Ferguson Pty. Ltd, Brisbane

Gower JC (1971) Statistical methods of comparing different multivariate analyses of the same data. In: Hodson FR, Kendall DG, Tautu P (eds) Mathematics in the archaeological and historical sciences. Edinburgh University Press, Edinburgh, pp 138-149

Harriott VJ (1985) Mortality rates of scleractinian corals before and during a mass bleaching event. Mar Ecol Prog Ser 21:81-88

Harvell CD, Mitchell CE, Ward JR, Altizer S, Dobson SP, Ostfeld RS, Samuel MD (2002) Climate warming and disease risks for terrestrial and marine biota. Science 296:2158-2162

Hoegh-Guldberg O (1999) Climate change, coral bleaching and the future of the world's coral reefs. Mar Freshw Res 50:839-866

Hughes TP (1994) Catastrophes, phase shifts, and large-scale degradation of a Caribbean coral reef. Science 265:1547-1551
Hughes TP, Baird AH, Bellwood DR, Card M, Connolly S, Folke C, Grosberg R, Hoegh-Guldberg O, Jackson JBC, Kleypas J, Lough JM, Marshall P, Nystrom M, Palumbi SR, Pandolfi JM, Rosen B, Roughgarden J (2003) Climate change, human impacts, and the resilience of coral reefs. Science 301:929-933

Huston MA (1985) Patterns of species diversity on coral reefs. Annu Rev Ecol Syst 16:149-177

Kinzie RA III, Buddemeier RW (1996) Reefs happen. Global Change Biol 2:479-494

Kleypas JA, Buddemeier RW, Archer D, Gattuso JP, Langdon C, Opdyke BN (1999) Geochemical consequences of increased atmospheric carbon dioxide on coral reefs. Science 284:118-120

Knowlton N (1992) Thresholds and multiple stable states in coral reef community dynamics. Am Zool 32:674-682

Lang J (1973) Interspecific aggression by scleractinian corals. 2. Why the race is not only to the swift. Bull Mar Sci 23:260-279

Ninio R, Meekan M, Done TJ, Sweatman H (2000) Temporal patterns in coral assemblages on the Great Barrier Reef from local to large spatial scales. Mar Ecol Prog Ser 194:65-74

Pearson RG (1981) Recovery and recolonization of coral reefs. Mar Ecol Prog Ser 4:105-122

Peres-Neto PR, Jackson DA (2001) How well do multivariate data sets match? The advantages of a Procrustean superimposition approach over the Mantel test. Oecologia 129:169-178

Pratchett MS (2005) Dynamics of an outbreak population of Acanthaster planci at Lizard Island, northern Great Barrier Reef (1995-1999). Coral Reefs 24:453-462

McCulloch M, Fallon S, Wyndham T, Hendy E, Lough J, Barnes D (2003) Coral record of increased sediment flux to the inner Great Barrier Reef since European settlement. Nature 421:727-730

R Development Core Team (2005) R: A language and environment for statistical computing. R Foundation for Statistical Computing, Vienna

Rosenberg E, Ben-Haim Y (2002) Microbial diseases of corals and global warming. Environ Microbiol 4:318-326

Seymour RM, Bradbury RH (1999) Lengthening reef recovery times from crown-of-thorns outbreaks signal systemic degradation of the Great Barrier Reef. Mar Ecol Prog Ser 176:1-10

Sheppard CRC (1985) Unoccupied substrate in the central Great Barrier Reef: role of coral interactions. Mar Ecol Prog Ser 25:259-268

Sweatman H, Bass DK, Cheal AJ, Coleman G, Miller IR, Ninio R, Osborne K, Oxley WG, Ryan DAJ, Thompson AA, Tompkins P (1998) Long-term monitoring of the Great Barrier Reef, Status Report Number 3. Australian Institute of Marine Science, Townsville

Tanner JE, Hughes TP, Connell JH (1994) Species coexistence, keystone species, and succession: a sensitivity analysis. Ecology 75:2204-2219

van Woesik R, Ayling AM, Mapstone B (1991) Impact of tropical cyclone 'Ivor' on the Great Barrier Reef, Australia. J Coast Res 7:551-558

Wilkinson CR (1999) Global and local threats to coral reef functioning and existence: review and predictions. Mar Freshw Res 50:867-878

Wooldridge S, Berkelmans R, Done TJ, Jones RN, Marshall P (2005) Precursors for resilience in coral communities in a warming climate: a belief network approach. Mar Ecol Prog Ser 295:157169 